\title{
Percepção dos Estudantes sobre a Implantação de uma Disciplina Regular de Pensamento Computacional em um Colégio de Educação Básica
}

\author{
André Luís Alice Raabe ${ }^{123}$, Elieser Ademir de Jesus ${ }^{1}$, Eduardo Alves da Silva, \\ Natália Ellery Ribeiro Couto ${ }^{3}$ \\ ${ }^{1}$ Laboratório de Inovação Tecnológica na Educação - CTTMar - UNIVALI \\ ${ }^{2}$ Programa de Pós-Graduação em Educação \\ ${ }^{3}$ Mestrado em Computação Aplicada \\ \{raabe, eas, elieser\}@univali.br, nataliaellery@gmail.com
}

\begin{abstract}
This paper presents the students' perception about the implementation of a regular Computational Thinking discipline in a Basic Education school. The discipline is offered from the 6th year of elementary school to the 3rd year of high school. The teaching strategies applied during the classes are presented, as well as the data collected from students' different perceptions about Computational Thinking. Most part of the students perceive the instigation of logical reasoning, creativity, working together, the importance of applying the Computational Thinking in their personal lives and in society. Other results synthesize the opinions about the difficulties of the contents and activities, the interdisciplinarity and the technological empowerment.
\end{abstract}

Resumo. Este artigo apresenta a percepção dos estudantes acerca da implantação de uma disciplina regular de Pensamento Computacional em uma escola de Educação Básica. A disciplina é ofertada do $6^{\circ}$ ano do Ensino Fundamental ao $3^{\circ}$ ano do Ensino Médio. São apresentadas as estratégias de ensino aplicadas durante as aulas, bem como os dados coletados sobre diferentes percepções dos estudantes sobre o Pensamento Computacional. Em sua maioria, os alunos percebem a instigação do raciocínio lógico, criatividade, trabalho em conjunto, a importância da aplicação do Pensamento Computacional. Outros resultados sintetizam as opiniões sobre as dificuldades das atividades, a interdisciplinaridade e o empoderamento tecnológico.

\section{Introdução}

O termo Pensamento Computacional (PC) surgiu em um artigo de opinião publicado por Wing em 2006, sendo conceituado como a síntese do conjunto de habilidades cognitivas que os profissionais da área da Computação geralmente desenvolvem em seu processo de formação. Em seu artigo ela sugere que, assim como habilidades fundamentais como a leitura, escrita e aritmética, que são as referências da alfabetização americana, o PC deve ser encorajado desde a Educação básica (Wing 2006). Desde então surgiram diversas iniciativas para incluir a abordagem do PC em escolas de educação básica.

Após 10 anos da publicação de Wing apresentando o PC, Heintz et al (2016) conduziram uma pesquisa para sintetizar a implantação de disciplinas que envolvem PC e Ciência da Computação desde a alfabetização até o Ensino Médio (EM) em 10 países: 
Austrália, Inglaterra, Estônia, Finlândia, Nova Zelândia, Noruega, Suécia, Coréia do Sul, Polônia e Estados Unidos. Alguns destes países incorporaram a Ciência da Computação no currículo oficial, enquanto outros estão no processo de incorporação. $O$ sistema educacional é diferente em cada país, mas através da análise dos autores é possível perceber no Ensino Fundamental (EF) uma tendência em apresentar a Ciência da Computação por meio do PC, lógica de programação ou competências digitais. Enquanto no EM a Ciência da Computação é apresentada de forma mais ampla, assim como seus impactos na sociedade.

$\mathrm{Na}$ literatura estrangeira existem trabalhos avaliando os resultados da implantação de disciplinas envolvendo a computação. Sabbagh et al (2017) apresentam um relatório de experiência sobre o currículo de computação no EF II em Qatar. O currículo aborda conceitos de programação, análise, pensamento lógico, e habilidades de resolução de problemas no contexto de criação de animações. Foram realizadas entrevistas em grupo e aplicados questionários para investigar a satisfação com as aulas e as impressões sobre as ferramentas utilizadas.

Nos Estados Unidos, DeLyser et al (2016) investigaram 4 escolas que possuem a computação em sua matriz curricular. Foram aplicados questionários com perguntas referentes ao efeito pedagógico, experiência com o professor, engajamento dos colegas na sala de aula e interesse dos estudantes no assunto. Já Dettori et al (2016) apresentam em seu trabalho a experiência de realizar um workshop com professores tendo como objetivo a disseminação do currículo Exploring Computer Science. Após o workshop, os professores aplicaram o currículo em suas aulas, e 7 destes professores aplicaram questionários para investigar a percepção de seus estudantes sobre as áreas da computação, utilidade do campo da computação e satisfação com o currículo ECS.

No Brasil também existem iniciativas para abordar o PC em escolas de educação básica. Aono et al (2017) realizaram um minicurso através do Scratch enquanto Reis et al (2017) utilizaram o site code.org e as atividades da Computação Desplugada em um curso para estudantes do EF. O SESI-PB, através de seu Programa Educação Básica articulada com Educação Profissional, integrou ao seu currículo o ensino de Robótica para o $1^{\circ}$ ano do EM. Souza et al (2016) apresentam os resultados da abordagem do PC integrado à disciplina de Robótica. Apesar de existirem diversas abordagens, elas não acontecem no formato de uma disciplina específica sobre PC presente na matriz curricular. Este formato (disciplina regular de PC) traz desafios ainda não explorados nas publicações encontradas e são importantes para o amadurecimento da área no Brasil.

Este artigo relata a percepção dos estudantes sobre a implantação do PC como disciplina obrigatória no EF e EM no Colégio de Aplicação da Universidade do Vale de Itajaí (UNIVALI) . A disciplina é ofertada para todos os estudantes do $6^{\circ}$ ano do EF até o $3^{\circ}$ ano do EM em 3 unidades do colégio, atendendo aproximadamente 700 estudantes. $\mathrm{O}$ artigo também apresenta as estratégias e ferramentas de ensino utilizadas pelos professores responsáveis pelas turmas em que os dados foram coletados.

$\mathrm{O}$ artigo está organizado como segue: $\mathrm{Na}$ Seção 2 detalha-se a estratégia de implantação do PC no colégio. Na seção 3 é apresentada a metodologia utilizada para coletar os dados referentes às percepções dos alunos sobre a disciplina. Por fim, na seção 4 são apresentadas as conclusões do trabalho e recomendações para gestores interessados em implantar uma disciplina semelhante. 


\section{Implantação da Disciplina de Pensamento Computacional no Colégio de Aplicação da UNIVALI}

Em 2017, o Colégio de Aplicação da UNIVALI (CAU) reorganizou sua matriz curricular com o objetivo de aderir às novas políticas públicas do Brasil. Desta maneira foi adotada a modalidade de ensino integral para os alunos entre o $6^{\circ}$ ano do EF II e $3^{\circ}$ ano do EM. Com esta oportunidade surgiram novas disciplinas obrigatórias e optativas, fazendo com que pesquisadores de Informática na Educação da UNIVALI realizassem a recomendação de inclusão de duas disciplinas.

A primeira disciplina, denominada Laboratório Maker, é optativa e aborda a vivência de projetos "mão na massa" incorporando diversas modalidades como marcenaria, costura, robótica, impressão 3D, entre outros. A segunda disciplina, denominada Pensamento Computacional, estimula a fluência em computação nos estudantes para que possam aplicar os conhecimentos e recursos em resolução de problemas e também a criação de aplicações por meio da programação.

A disciplina de PC passou então a ser oferecida de forma obrigatória para todos estudantes do $6^{\circ}$ ano do EF ao $3^{\circ}$ ano do EM nas três unidades do Colégio, localizadas nos municípios de Itajaí, Balneário Camboriú e Tijucas no estado de Santa Catarina.

\subsection{Definição dos conteúdos}

No primeiro ano de implantação a matriz curricular foi criada para que todos os estudantes pudessem ter um contato inicial com a disciplina, já que estariam tendo os primeiros contatos com o PC. Conforme os estudantes forem avançando para o ano seguinte, a matriz curricular será reformulada possibilitando uma progressão do $6^{\circ}$ ano do EF até o $3^{\circ}$ ano do EM. No primeiro ano as ementas foram divididas em 3 grupos:

- EF II - $6^{\circ}$ e $7^{\circ}$ ano - Estudo dos dispositivos computacionais, Mecanismos de busca, Noção de algoritmos, Práticas de computação, Jogos de lógica, Construção de narrativas usando programação com blocos;

- EF II - $8^{\circ}$ e $9^{\circ}$ ano - Fundamentos de computação, Funcionamento dos mecanismos de busca, Algoritmos com condições e repetições, Animação e som, Construção de animações usando programação com blocos;

- EM - Fundamentos de computação, Funcionamento dos mecanismos de busca, Algoritmos com condições e repetições, Animação e Som, Construção de animações usando programação, Algoritmos que manipulam dados, Projetos de aplicações.

\subsection{Estratégias e Ferramentas Utilizadas nas Aulas}

A disciplina de PC foi ministrada por 2 professores e 1 professora: o primeiro responsável por 4 turmas de $6^{\circ}$ e $7^{\circ}$ ano do CAU de Itajaí; o segundo responsável por 10 turmas de $8^{\circ}$ ano do EF a $3^{\circ}$ ano do EM do CAU de Itajaí; e a professora responsável por 10 turmas de $8^{\circ}$ ano do EF a $3^{\circ}$ ano do EM do CAU de Balneário Camboriú. As aulas possuem duração de 45 minutos e acontecem uma vez na semana. Cada professor criou seus planos de ensino e utilizou diferentes estratégias para trabalhar os conteúdos da ementa definidos para a disciplina, as quais são apresentadas a seguir.

\subsubsection{Estratégias e Ferramentas utilizadas com o $6^{\circ}$ e $7^{\circ}$ anos}

As turmas dos $6^{\circ}$ e $7^{\circ}$ anos (4 turmas no total) vivenciaram pela primeira vez o PC 
enquanto disciplina regular. Grande parte da disciplina aconteceu sob a forma de pequenos projetos práticos, realizados na sala de aula ou no laboratório de informática ao longo de algumas semanas (1 encontro por semana).

Já na primeira aula os estudantes foram desafiados a descobrir o que era "Pensamento Computacional" e ficaram muito felizes ao saber que poderiam usar o telefone celular para fazer a pesquisa. Em seguida, o professor apresentou uma noção geral de algoritmo e a turma realizou uma atividade na qual cada dupla escreveu a sequência de passos (usando setas direcionais) para sair da sua carteira e chegar até a porta da sala (o chão da sala de aula é quadriculado).

Desde a primeira aula ficou bastante evidente a pouca capacidade dos estudantes (entre 10 e 12 anos) de se manterem focados durante explicações orais. Por conta disso, todo o restante da disciplina foi pensada com o objetivo de reduzir (e às vezes até eliminar) tais explicações, substituindo-as por pesquisas e consulta de materiais (tutoriais, video aulas, etc) selecionados e indicados pelo professor.

$\mathrm{Na}$ aula seguinte, ainda em sala de aula, foram utilizados jogos de lógica (BloxorZ ${ }^{1}$ e LightBot ${ }^{2}$ ), os estudantes anotavam os algoritmos usados para passar alguns níveis, e depois trocavam os algoritmos entre si e executavam/testavam os algoritmos dos colegas buscando, por exemplo, passos faltantes para completar os níveis do jogo.

$\mathrm{Na}$ terceira aula a turma foi para o laboratório de informática (algo muito aguardado por eles) e os estudantes resolveram (em duplas) o desafio do jogo MineCraft no site code.org. Esta atividade teve uma enorme importância em grande parte do que aconteceu em seguida na disciplina. O Scratch ${ }^{3}$ foi utilizado como principal ferramenta durante todo o ano e o desafio do site code.org foi, na visão do professor, a introdução mais intuitiva possível à ideia da programação em blocos (noção fundamental para a utilização do Scratch).

$\mathrm{Na}$ aula seguinte o Scratch foi apresentado para a turma, e após a experiência com o site code.org os estudantes não tiveram dificuldades para compreender $\mathrm{o}$ funcionamento da ferramenta, conseguindo realizar atividades simples (animar personagens, fazer o personagem "falar", etc). Nas 3 aulas seguintes os estudantes (em duplas ou trios) trabalharam no primeiro projeto prático da disciplina: uma história interativa feita no Scratch, incluindo diálogos, animação de personagens e troca de tela de fundo.

Nas aulas seguintes o professor fez breves explicações sobre como movimentar os personagens do Scratch usando o teclado do computador e como verificar se os objetos estavam "tocando" uns nos outros. Em seguida os estudantes dedicaram as aulas restantes do $1^{\circ}$ bimestre para trabalhar (em duplas ou trios) no $2^{\circ}$ projeto prático: um jogo simples (tema livre) no qual seria possível controlar pelo menos um personagem e deveria haver teste de colisão. Durante a realização destes projetos práticos o professor auxiliou cada equipe com as dúvidas específicas do seu projeto. Apesar de muito intensa e cansativa esta abordagem mostrou-se mais produtiva do que a tradicional "explicação que vale para todos", já que este público (entre 10 e 12 anos de idade) demonstrou desde o início uma grande dificuldade em acompanhar explicações orais.

\footnotetext{
${ }^{1} \mathrm{http}: / /$ www.coolmath-games.com/0-bloxorz

${ }^{2}$ http://lightbot.com/

${ }^{3} \mathrm{https}: / /$ scratch.mit.edu/
} 
Ao final do segundo projeto prático com o Scratch as duplas apresentaram seus trabalhos para toda a turma. As quatro turmas mostraram-se muito empolgadas pela possibilidade de apresentar seus projetos para os colegas, tendo o jogo projetado em uma tela grande através do data show.

Após a realização dos dois primeiros projetos práticos os estudantes estavam visivelmente cansados da ferramenta Scratch. Por este motivo, o projeto realizado a seguir foi uma máquina de Rube Goldberg, uma atividade totalmente desplugada. Em um primeiro momento os estudantes (divididos em quartetos) esboçaram em papel como seria a máquina, quais materiais seriam usados para construí-la e quem ficaria responsável por trazer cada material necessário para a construção. $\mathrm{Na}$ aula seguinte, para surpresa do professor, a sala estava repleta de caixas de dominó, papelão, bolinhas de gude, canos de PVC, patins, ventilador, secador de cabelo, pistolas de cola quente, etc., todos os materiais trazidos de casa pelos estudantes (ver Figura 1).

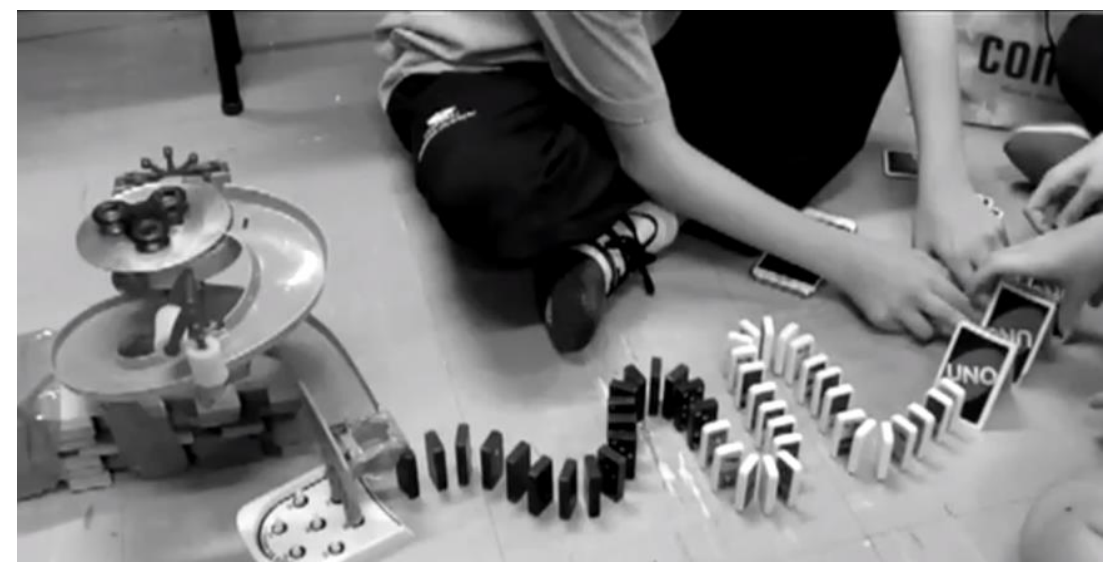

Figura 1. Máquina de Rube Goldberg feita com brinquedos no chão da sala

As aulas seguintes foram dedicadas à montagem e teste da máquina de Rube Goldberg (cada equipe projetou sua própria máquina) na sala de aula, usando todos os objetos disponíveis no ambiente (chão, mesas, carteiras, quadro, etc.). Além de desenvolver a resiliência e a capacidade de trabalhar em equipe esta atividade propiciou um intenso exercício de aprimoramento da habilidade de resolução de problemas. Todas as equipes se depararam com inúmeras situações nas quais a máquina real não funcionava como aquela desenhada no papel, tendo que buscar alternativas e em algumas situações até mesmo pensar em outra máquina.

Este projeto gerou excelentes resultados, muito engajamento por parte dos estudantes e também de alguns pais. A grande dificuldade observada foi a curta duração das aulas (aproximadamente 45 minutos), forçando a montagem e desmontagem das máquinas (algumas relativamente grandes) em cada aula. Ao final do projeto as máquinas em funcionamento foram filmadas, e cada equipe teve seu projeto avaliado pelos colegas de sala e também pelas outras 3 turmas, um momento de muito alegria e aprendizagem. Os vídeos das máquinas construídas estão disponíveis em http://pccau.appspot.com/.

O último projeto prático do ano letivo foi um projeto no Scratch, no qual os estudantes (em duplas) programaram uma simulação de uma das máquinas de Rube Goldberg construídas no trabalho prático anterior. Novamente cada equipe apresentou (geralmente com muito orgulho) seu trabalho para toda a turma. 
De forma geral, a abordagem baseada em pequenos projetos práticos com temas escolhidos pelos estudantes mostrou-se bastante satisfatória, tanto do ponto de vista dos estudantes quando do ponto de vista do professor. Vale mencionar que, ao contrário do que era esperado pelo professor, as diferenças entre as turmas de $6^{\circ}$ e $7^{\circ}$ anos foi muito significativa. A maturidade e capacidade de lidar com assuntos mais abstratos era notoriamente menor com o $6^{\circ}$ ano, exigindo do professor uma série de adaptações nas estratégias utilizadas.

Em uma das turmas havia uma estudante com deficiência visual. Isto gerou uma série de desafios no planejamento das aulas, já que o Scratch (principal ferramenta utilizada) não se integra com os softwares leitores de tela usados pelos deficientes visuais. Isto reduziu drasticamente as possibilidades para esta estudante, cuja aprendizagem depende muito de feedback auditivo.

\subsubsection{Estratégias e Ferramentas usadas com $8^{\circ}$ e $9^{\circ}$ anos e EM}

As aulas do $8^{\circ}$ ano do EF ao $3^{\circ}$ ano do EM da unidade de Itajaí foram conduzidas pela mesma professora. Ao iniciar o ano letivo foram criados planos de aula baseados nas duas primeiras atividades do material de apoio da Ciência da Computação Desplugada ${ }^{4}$ : Números Binários e Colorindo através de Números para tratar do tópico da disciplina PC: "Fundamentos de Computação". Em seguida os tópicos da ementa "Algoritmos com Condições e Repetições", "Animação e Som" e "Construção de Animações usando programação com Blocos" foram abordados simultaneamente ao utilizar a ferramenta Scratch. Os estudantes iniciaram as atividades no Scratch através da construção de animações, onde foram aplicados na prática os conceitos de algoritmos com repetição para programar o movimento e aparência dos componentes da animação. Da mesma forma o som foi abordado para complementar as animações construídas pelos estudantes.

O conceito de condições foi abordado através da criação de jogos com a ferramenta Scratch, os estudantes utilizaram algoritmos com condições para verificar colisão entre personagens, acionar eventos através da verificação de cliques do mouse ou teclas do teclado pressionadas. A seguir foi introduzido um novo tópico: "Algoritmos que manipulam dados", o qual não consta na ementa do EF II, mas que foi introduzido a estes alunos devido à facilidade dos mesmos em realizar as atividades referentes aos tópicos anteriores. Ao observar o desempenho dos estudantes do EF II foi percebido que eles conseguiram realizar as mesmas atividades que os estudantes do EM.

No fim do segundo bimestre foi possível completar os tópicos da ementa, então por decisão da professora, os bimestres seguintes foram utilizados para trabalhar os mesmos assuntos porém com o uso de ferramentas mais complexas, aprofundando os conhecimentos adquiridos e demonstrando aos estudantes que diversas ferramentas e linguagens de programação possuem a mesma base conceitual, a qual também é aplicada a processos de pensamento utilizados através do PC como: abstração, reconhecimento de padrões, sequenciamento de passos, entre outros. As aulas se deram em torno da ferramenta AppInventor ${ }^{5}$ que permite o desenvolvimento de aplicativos para dispositivos móveis.

\footnotetext{
${ }^{4}$ https://csunplugged.org/en/

${ }^{5} \mathrm{http}: / /$ appinventor.mit.edu
} 
As primeiras aulas do terceiro bimestre envolveram o desenvolvimento de projetos simples para entender a nova plataforma, a qual é voltada para componentes de dispositivos móveis. Foi possível perceber que os estudantes tiveram dificuldades com o novo ambiente, e não se mostraram empolgados com a criação de projetos pré-definidos pela professora. Para tornar as aulas mais agradáveis e produtivas foram realizadas votações para que cada turma pudesse escolher modelos de projetos para desenvolver, como por exemplo: jogos para celular, aplicativos de bate-papo, quiz, entre outros.

A abordagem de ensino escolhida para o terceiro bimestre acabou se tornando complexa demais para ser finalizada em um bimestre, então, com as turmas que concluíram as atividades - uma turma do $3^{\circ}$ ano, duas turmas do $2^{\circ}$ ano e duas turmas do $1^{\circ}$ ano-, foi possível abordar uma terceira ferramenta: o Portugol Studio ${ }^{6}$, enquanto as outras turmas - duas do $8^{\circ}$ ano, duas do $9^{\circ}$ e uma turma do $3^{\circ}$ ano - continuaram a trabalhar nos projetos do AppInventor. Esta nova ferramenta trouxe uma nova realidade: a programação escrita. Os estudantes não tinham mais os comandos em blocos para arrastar e encaixar, nem a facilidade gráfica de montar o projeto arrastando os componentes. Com esta ferramenta foram abordados os conceitos de manipulação de dados através de variáveis e o uso de desvios condicionais. Ao invés de trabalhar com foco em pequenos projetos, com o Portugol Studio foram lançados desafios de programação.

Através das aulas ministradas foi possível perceber que tanto os alunos do EF II quanto os alunos do EM foram capazes de realizar as mesmas atividades propostas. Ainda foi possível observar casos em que alunos do EF II alcançaram resultados mais complexos do que alunos do EM. Através desta observação seria possível sugerir que uma disciplina de PC não seja necessariamente separada por idades, e sim por nível de habilidade. Quanto aos temas abordados, o EF II se mostrou bastante empolgado na criação de jogos e animações, enquanto o EM apresentou maior interesse pelo Portugol Studio, ferramenta que proporciona programação através de linguagem escrita ao invés de blocos.

Um fator que chamou a atenção foi a integração das estudantes nas atividades e participação das aulas: em algumas turmas as estudantes mostraram maior interesse do que os estudantes. Atualmente ainda existem poucas garotas cursando o ensino superior na área da computação (Santos 2017), o que pode sugestionar que garotas não gostam desta área ou que possuem dificuldades com este tipo de conteúdo. Entretanto, não foi o que aconteceu durante as aulas de PC.

\section{Percepção dos Estudantes sobre a Disciplina de PC}

Foram utilizados dois questionários para a coleta de dados em relação à percepção dos estudantes sobre a disciplina. O Questionário $1^{7}$ teve como objetivo uma análise exploratória com perguntas de respostas abertas sobre a opinião dos estudantes em relação aos pontos positivos, negativos e melhorias que poderiam acontecer nas aulas. Foi aplicado no $2^{\circ}$ bimestre de $2017 \mathrm{com}$ as turmas do $8^{\circ}$ ano do EF ao $3^{\circ}$ ano do EM da unidade de Itajaí. A escolha da amostra para o Questionário 1 ocorreu por questões de logística, já que estas turmas eram ministradas pela mesma professora. O questionário foi facultativo e em anonimato - com o objetivo de que os estudantes respondessem de

\footnotetext{
${ }^{6} \mathrm{http}: / /$ lite.acad.univali.br/portugol/

${ }^{7}$ https://bit.ly/2jloka4
} 
forma sincera sem o receio de serem prejudicados posteriormente. No Questionário $2^{8}$, as questões foram elaboradas com base nas respostas analisadas do Questionário 1, com a finalidade de investigar em maior profundidade a opinião dos estudantes em relação aos tópicos sugeridos por eles mesmos em suas respostas. Este questionário também foi facultativo e em anonimato, aplicado no último dia de aula e contou com a resposta de 403 estudantes do $8^{\circ}$ ano do EF ao $3^{\circ}$ ano do EM do CAU de Itajaí e Tijucas, os estudantes do CAU de Balneário Camboriú não participaram por falta de disponibilidade no período de encerramento das aulas.

Os detalhes sobre cada questionário aplicado aos estudantes são apresentados a seguir.

\subsection{Questionário 1}

O Questionário 1 foi composto por 3 questões abertas. Nas duas primeiras os estudantes descreveram os pontos positivos e negativos sobre PC enquanto disciplina obrigatória, e na Pergunta 3 sugeriram melhorias para as aulas.

Um total de 138 estudantes responderam ao questionário. Foram criadas categorias baseadas nas respostas textuais dos estudantes e algumas respostas acabaram se enquadrando em mais de uma categoria, já que a pergunta sugere uma resposta aberta. Por exemplo, a resposta "O aumento do raciocínio lógico e a quebra da sala de aula'. " foi enquadrado na categoria Estimular o pensamento lógico elou criatividade e também na categoria Dinâmica diferenciada das aulas tradicionais - neste caso a resposta de um estudante contabilizou para duas categorias, então o total de itens categorizados ultrapassa o número de respostas dos estudantes. A Tabela 1 apresenta as categorias de respostas para a Pergunta 1 (Descreva algo positivo de consequência da disciplina de Pensamento Computacional) e a sua frequência nos dados coletados.

Tabela 1. Categorias para as respostas da Pergunta 1

\begin{tabular}{|l|l|l|}
\hline Categoria & Frequência & Percentual \\
\hline 1 - Aprender coisas novas & 82 & $48.52 \%$ \\
\hline 2 - Dinâmica diferenciada das aulas tradicionais & 51 & $30.17 \%$ \\
\hline 3 - Estimular pensamento lógico e/ou criatividade & 27 & $15.97 \%$ \\
\hline 4 - Influenciar a realizar graduação na área & 1 & $0.59 \%$ \\
\hline 5 - Não opinou & 8 & $4.73 \%$ \\
\hline \multicolumn{1}{|c|}{ Total } & 169 & $100 \%$ \\
\hline
\end{tabular}

A categoria Aprender coisas novas aparece mais frequentemente entre as respostas com $48.52 \%$, o que é o resultado esperado já que este foi o primeiro ano de implantação da disciplina e os estudantes não possuíam conhecimentos sobre o assunto através da escola.

A categoria Dinâmica diferenciada das aulas tradicionais aparece em 30.17\% das respostas, podendo ser justificada pelo fato de a maioria das aulas serem realizadas no laboratório de informática e em duplas, e normalmente requerendo mais "mão-namassa" do que a atenção voltada para o professor explicando novos conceitos.

A categoria Estimular pensamento lógico elou criatividade, com $15.97 \%$ das respostas, está relacionada aos trabalhos e atividades realizados durante as aulas. Como

\footnotetext{
${ }^{8} \mathrm{https}: / / g o o . g l / f o r m s / A h o a g S n T w H H i U C W S 2$
} 
em muitas dessas atividades o tema era livre os estudantes utilizavam a criatividade para criar projetos relacionados do seu interesse.

A categoria Influenciar a realizar graduação na área foi apontada em apenas uma das respostas, ou seja, apenas um estudante mencionou este argumento como ponto positivo.

Por fim, Não opinou foi a categoria utilizada para aqueles estudantes que responderam o questionário, porém não expressaram suas opiniões sobre os pontos positivos da disciplina, representando $4.73 \%$ das respostas.

A Pergunta 2 teve como objetivo analisar os pontos negativos que a aula pode ter proporcionado aos estudantes em sua vida acadêmica, já que este estudo tem como objetivo analisar a percepção dos estudantes como um todo, não apenas os benefícios. É necessário descobrir os pontos negativos para saber em quais pontos as aulas poderiam ser reformuladas, quais estratégias de ensino podem não funcionar como desejado. A Tabela 2 apresenta as categorias criadas a partir das respostas para a segunda pergunta: Descreva algo de negativo de consequência da disciplina de Pensamento Computacional.

Tabela 2. Categorias para as respostas da Pergunta 2

\begin{tabular}{|l|l|l|}
\hline Categoria & Frequência & Percentual \\
\hline 1 - Estratégia de ensino & 40 & $25.31 \%$ \\
\hline 2 - Não vêem importância & 29 & $18.35 \%$ \\
\hline 3 - Infraestrutura & 13 & $8.22 \%$ \\
\hline 4 - Não opinou & 60 & $37.97 \%$ \\
\hline 5 - Dificuldade & 10 & $6.32 \%$ \\
\hline 6 - Comportamento dos colegas & 6 & $3.79 \%$ \\
\hline TOTAL & 158 & $100 \%$ \\
\hline
\end{tabular}

Com $37.97 \%$ do total, a maioria dos estudantes não expressou sua opinião. A próxima categoria mais frequente é a Estratégia de ensino com $25.31 \%$ das respostas. Analisando as respostas foi possível perceber muitas críticas sobre o uso excessivo da ferramenta Scratch, utilizada em 15 aulas (aproximadamente 4 meses). De acordo com as respostas dos estudantes este tempo utilizando uma mesma ferramenta tornou as atividades repetitivas e cansativas.

A categoria Não vêem importância apareceu em $18.35 \%$ das respostas, o que se refletia na sala de aula, pois alguns estudantes afirmaram que não reconheciam a importância da disciplina em sua vida acadêmica ou futuro profissional.

A Infraestrutura foi mencionada como ponto negativo para $8.22 \%$ dos estudantes. Nesta categoria foram encontradas respostas sobre o aumento ou diminuição da carga horária, tornar a disciplina opcional, a distância entre o laboratório e a sala de aula, a necessidade de um professor extra, entre outros.

A categoria Dificuldade envolveu $6.32 \%$ das respostas e $3.79 \%$ das respostas trataram da categoria Comportamento dos colegas devido à bagunça excessiva que ocorria durante as aulas.

A Pergunta 3 foi criada com o intuito de entender como melhorar os pontos negativos apresentados pelos estudantes. Por ter sido aplicado no segundo bimestre, o questionário também poderia ser utilizado para melhorar as aulas do terceiro e quarto 
bimestres. A Tabela 3 apresenta as categorias criadas para as respostas da pergunta Existe algo na disciplina de Pensamento Computacional que você acha que poderia melhorar? O quê?

Tabela 3. Categorias para as respostas da Pergunta 3

\begin{tabular}{|l|l|l|}
\hline Categoria & Frequência & Percentual \\
\hline 1 - Sem opinião & 48 & $33.56 \%$ \\
\hline 2 - Alterar estratégia de ensino & 78 & $54.54 \%$ \\
\hline 3 - Alterar a infraestrutura & 9 & $6.29 \%$ \\
\hline 4 - Rigidez comportamental & 7 & $4.89 \%$ \\
\hline 5 - Tudo & 1 & $0.69 \%$ \\
\hline TOTAL & 143 & $100 \%$ \\
\hline
\end{tabular}

A maioria das respostas envolveram a sugestão de alterar a ferramenta utilizada nas atividades de sala de aula na categoria Alterar estratégia de ensino com $54.54 \%$ das respostas. Este resultado é consistente com as respostas relacionadas aos pontos negativos mencionados na Pergunta 2, na qual a segunda categoria mais frequente também é a Estratégia de ensino. Um total de $33.56 \%$ dos respondentes não apresentou opinião sobre possíveis melhorias para as aulas.

As respostas que incluíram a categoria Alterar a infraestrutura consistiram em $6.29 \%$ do total, sugerindo alterar o tempo de aula, o auxílio de um segundo professor para sanar as dúvidas específicas de cada estudante ou transformar a disciplina em opcional. Por fim, a categoria Rigidez comportamental totalizou $4.89 \%$ das respostas, sugerindo tratamento mais duro com estudantes agitados. Um estudante sugeriu que tudo deveria ser melhorado, representando $0.69 \%$ dos respondentes.

\subsection{Questionário 2}

O Questionário 2 foi composto por 14 questões as quais foram respondidas através de uma escala numérica com valores de 0 a 5 . O valor 5 representando "Muito", o valor zero representando "Nada", o valor 1 representando "Pouco", e os números 2, 3 e 4 representando valorações intermediárias entre pouco e muito. As perguntas foram elaboradas com base nas categorias criadas a partir das respostas do Questionário 1. A realização do questionário foi facultativa e também se deu de forma anônima. $\mathrm{O}$ questionário foi aplicado no último dia de aula e contou com a resposta de 403 estudantes do CAU de Itajaí e Tijucas.

A Questão 1 e 2 investigaram o uso da criatividade e o estímulo do raciocínio lógico na disciplina de PC. Nos dois casos a resposta mais frequente foi 5 - Muito. Isso pode ser confirmado pela observação em sala de aula, os estudantes tiveram bastante liberdade para escolher diferentes temas para a criação de seus projetos e o pensamento lógico estava presente nas construções de algoritmos e resolução de problemas.

A Questão 3 tinha o objetivo de compreender as diferenças da disciplina de PC em comparação com as outras disciplinas regulares. Novamente a resposta mais frequente foi 5 - Muito. Este resultado pode ser justificado pelo frequente uso do laboratório de informática, trabalhos práticos em dupla e atividades voltadas a desenvolvimento de projetos.

A Questão 4 abordou o interesse pessoal em aprender a fazer jogos, aplicativos ou programar. Essa questão foi elaborada porque no Questionário 1 apareceram 29 
respostas enquadradas na categoria Não vêem importância, apontada como ponto negativo. As respostas mostraram que 162 estudantes acharam Muito (5) interessante aprender a fazer jogos, aplicativos ou programar, sendo esta a resposta mais frequente, enquanto apenas 17 respondentes (4.2\%) não demonstraram interesse. A Figura 2 apresenta a distribuição das respostas.
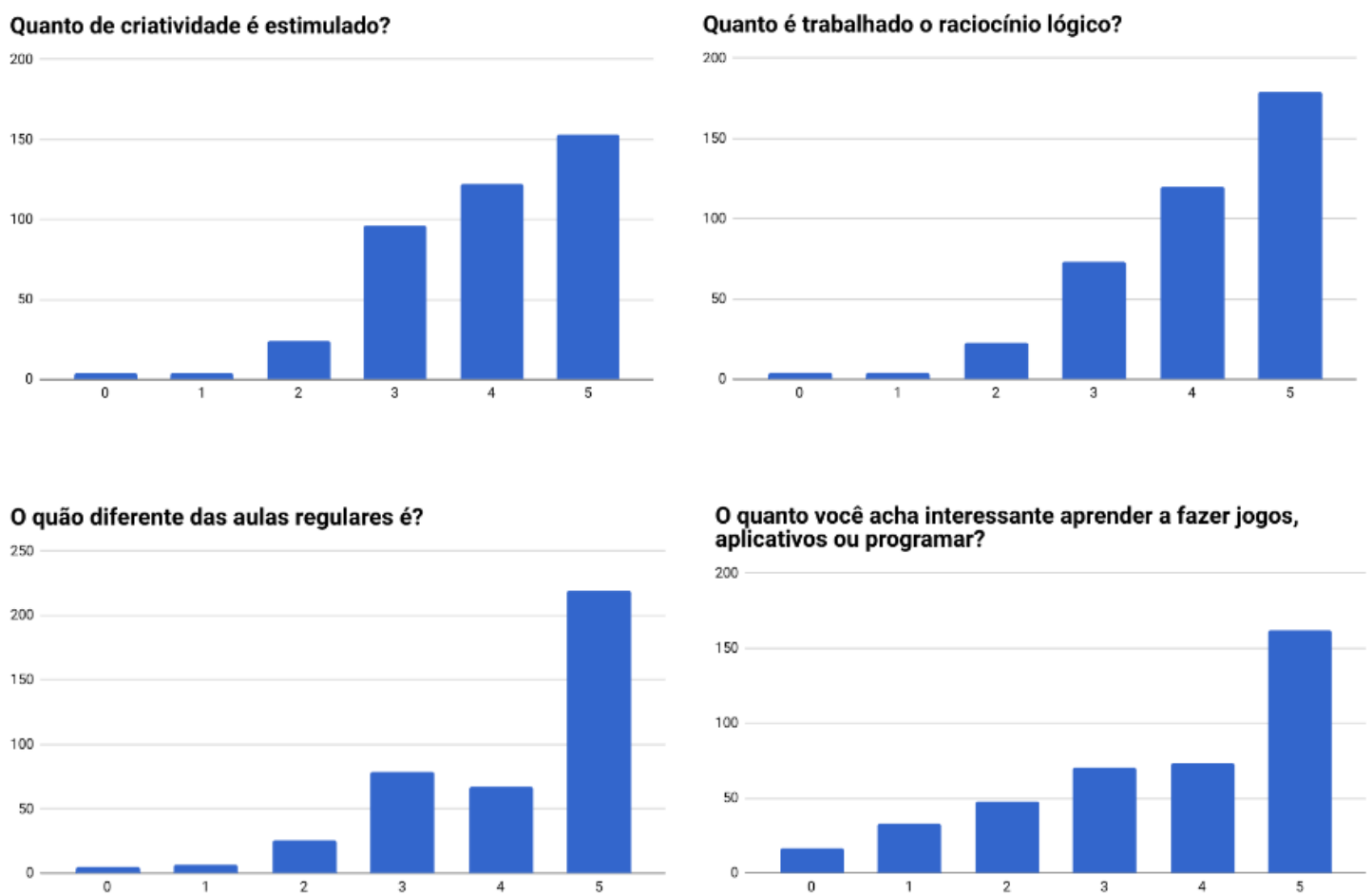

Figura 2. Respostas da Questão 1 (superior esquerdo), Questão 2 (superior direito), Questão 3 (inferior esquerdo) e Questão 4 (inferior direito)

A Questão 5 trata da experiência em realizar trabalhos em equipe devido ao número limitado de computadores nos laboratórios de informática. A resposta mais frequente, com 137 respostas, foi novamente 5 (Muito). Através da observação foi possível perceber estudantes discutindo e planejando estratégias para desenvolver os projetos e resolver as atividades propostas.

A Questão 6 tratou da dificuldade em realizar as atividades e entender o conteúdo na disciplina de $\mathrm{PC}$, trazida no Questionário 1 por 10 respondentes como um ponto negativo da disciplina. A resposta mais frequente foi o grau 3, valor intermediário entre muito difícil (5) e pouco difícil (1). Durante as aulas era normal observar conversas paralelas e estudantes focando em outras coisas ao invés das explicações, isso dificultou um pouco a compreensão do conteúdo em diversos momentos.

A Questão 7 foi elaborada para tentar compreender quão boa a estratégia de ensino foi para a disciplina, já que este foi um ponto negativo apontado por 40 estudantes no Questionário 1. A resposta mais frequente foi 5, com 145 votos. Aqui se percebe uma mudança de opinião dos estudantes em relação a estratégia utilizada. Esta mudança de opinião pode ter ocorrido pelo fato de que a ferramenta que foi apontada 
como repetitiva e cansativa (Scratch) foi substituída por outras.

A Questão 8 tinha como objetivo investigar se a disciplina de alguma forma auxiliou na aprendizagem de outras disciplinas. A resposta não (0) apareceu em $23.1 \%$ do total, mas considerando que todas as outras alternativas afirmam que há algum auxílio mesmo que este seja pouco (1), é possível então afirmar que $76.9 \%$ dos estudantes percebem contribuição (ainda que pouca) do PC em outras disciplinas. A síntese destes dados é apresentada na Figura 3.
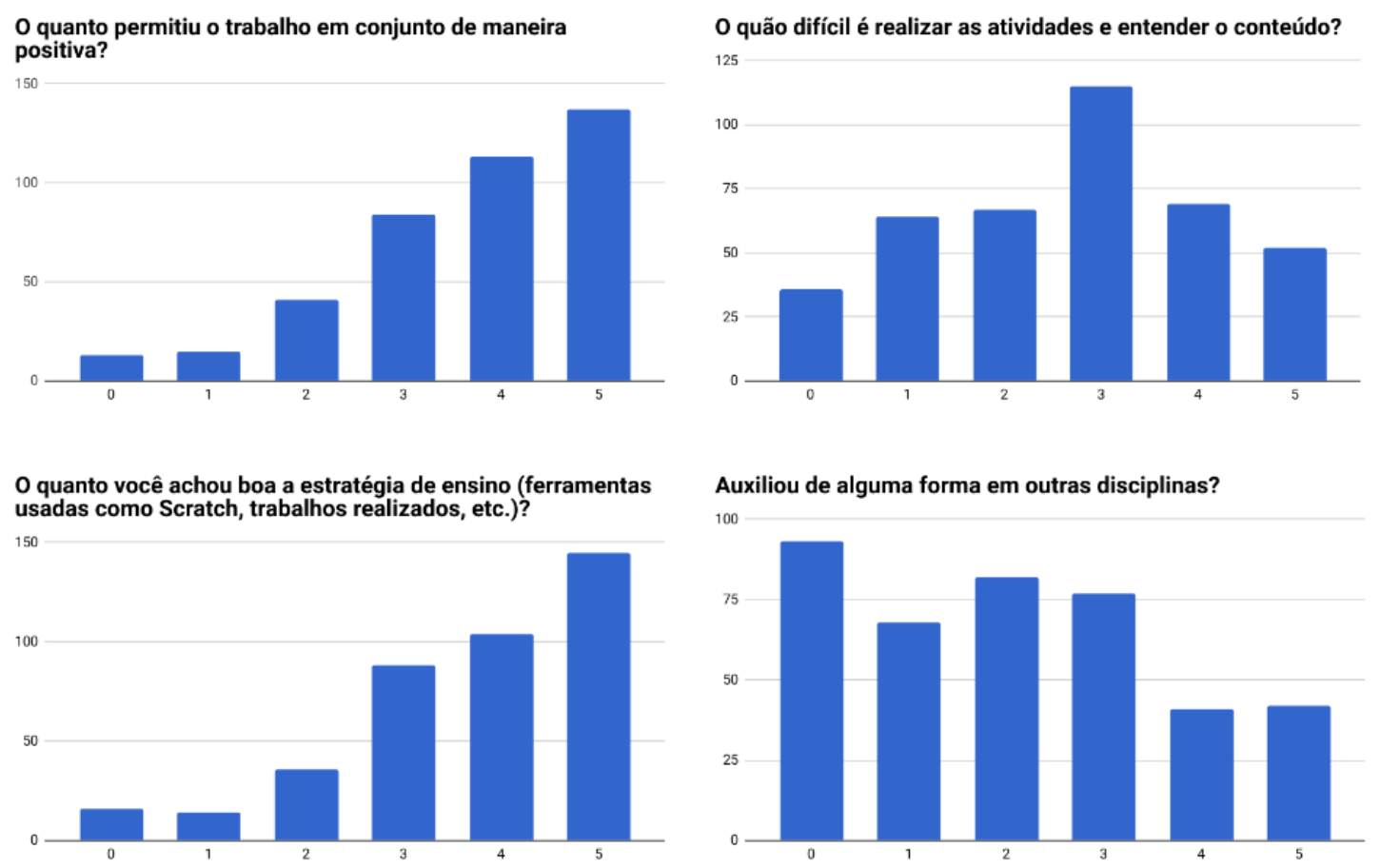

Figura 3. Respostas da Questão 5 (superior esquerdo), Questão 6 (superior direito), Questão 7 (inferior esquerdo) e Questão 8 (inferior direito)

As Questões 9 ( $O$ quanto você se interessava pela computação antes de ter a disciplina de pensamento computacional?) e 10 (O quanto você se interessa pela computação agora?) investigaram o interesse dos estudantes na área de computação antes e depois de participar da disciplina. $\mathrm{O}$ resultado das comparações mostrou um total de 210 estudantes informando que seu interesse em computação aumentou, enquanto 39 afirmam que o interesse diminuiu. Um total de 154 estudantes mantiveram o mesmo nível de interesse antes e depois, mas entre esses 79 escolheram a opção de interesse 5, ou seja, por ser a opção máxima não era possível explicitar um aumento do interesse.

A questão 11 abordou se o estudante se sentia capaz de criar um aplicativo ou programa que lhe podia ser útil. A resposta não (0) foi a mais frequente com $15.4 \%$ do total, mas todas as outras alternativas demonstraram uma percepção que existia alguma capacidade, mesmo que pouca (1). Sendo assim, é possível afirmar que $84.6 \%$ dos estudantes percebiam-se com alguma capacidade de criar aplicativos ou programas úteis para si mesmos. 
A questão 12 investigou o interesse dos alunos em cursar o ensino superior na área da computação. A resposta mais votada foi 0 - não influenciou na decisão de cursar - com 130 votos $(32.3 \%)$. Enquanto 47 estudantes $(11.7 \%)$ mencionaram que a disciplina influenciou um pouco (1), 49 alunos (12.2\%), manifestaram que influenciou muito (5), e os 177 estudantes restantes $(43.9 \%)$ utilizaram valores intermediários (1 a 3) para definir o grau de influência da disciplina a cursar o ensino superior na área da computação.

As questões 13 e 14 tiveram como objetivo investigar em maior profundidade o resultado do Questionário 1, no qual 29 estudantes apontaram a falta de importância ou utilidade da disciplina. Com os resultados da questão 13 é possível perceber que a maioria dos alunos (117) percebe o PC como muito útil (5) em suas vidas. Apenas 34 estudantes votaram 0 , o que representa $8.4 \%$ das respostas. A questão 14 apresentou $46.2 \%$ das respostas afirmando que o PC é muito útil (5) na sociedade, apenas $3.2 \%$ afirmam que não possui utilidade (0). A síntese destes dados é apresentada na Figura 4.
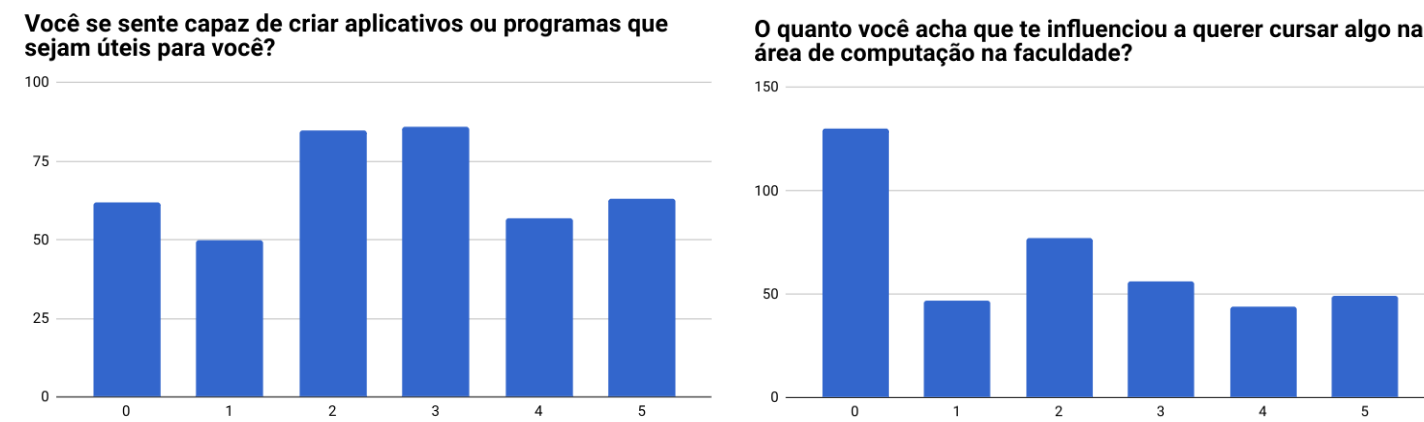

O quanto você acha que te influenciou a querer cursar algo na área de computação na faculdade? 150
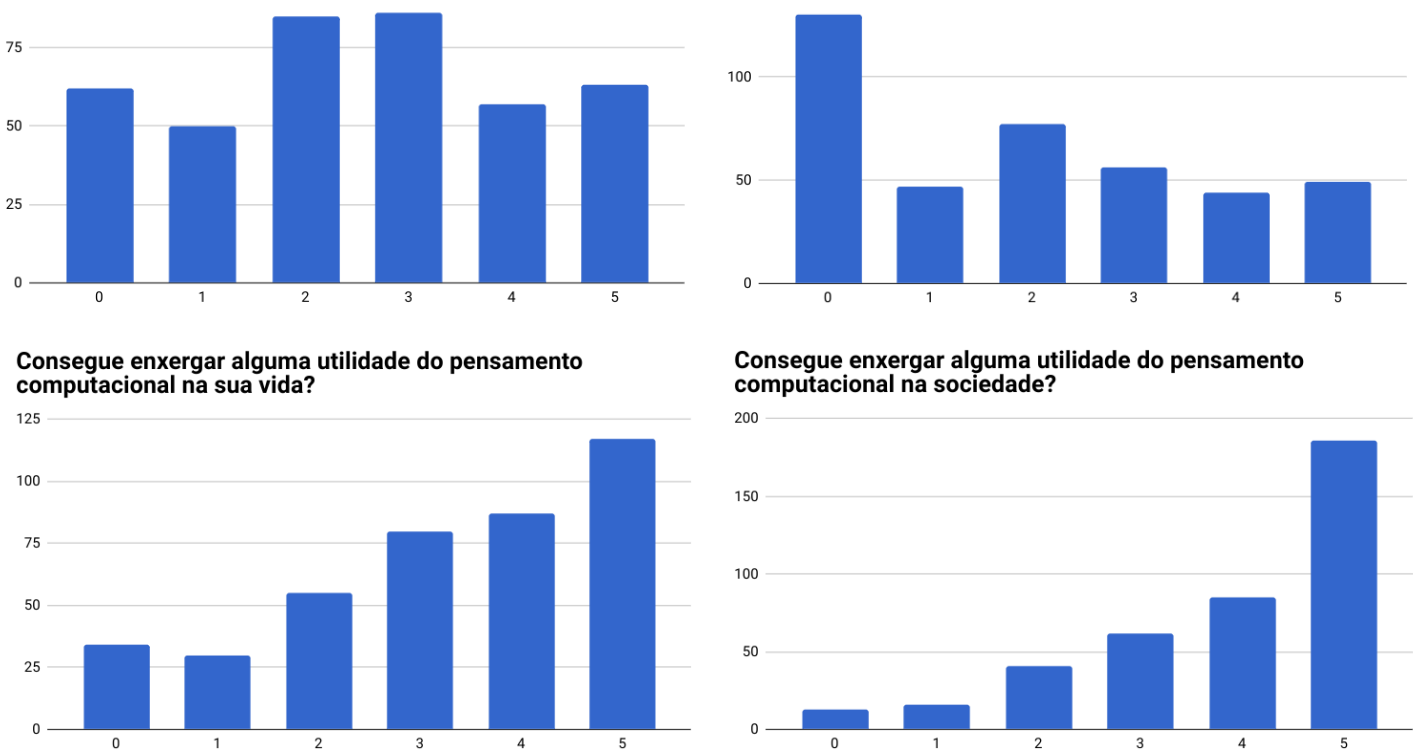

Consegue enxergar alguma utilidade do pensamento computacional na sociedade?

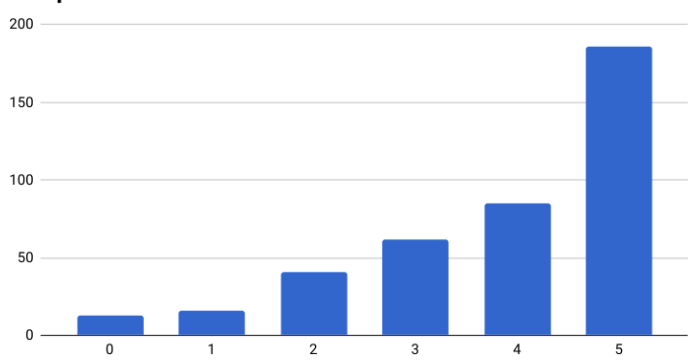

Figura 4. Respostas da Questão 11 (superior esquerdo), Questão 12 (superior direito), Questão 13 (inferior esquerdo) e Questão 14 (inferior direito)

\section{Conclusões}

Ao analisar os resultados é possível perceber que a maioria dos estudantes acredita que a disciplina de PC promoveu a criatividade, estimulou o raciocínio lógico, o trabalho em conjunto, e propiciou uma aula diferente das aulas tradicionais. As respostas apontam que os estudantes acharam interessante aprender a desenvolver jogos, aplicativos ou trabalhar com programação, e percebem a utilidade das habilidades desenvolvidas em sua vida pessoal e na sociedade.

A maioria dos estudantes afirma que as estratégias de ensino adotadas foram muito boas. Sobre a dificuldade atribuída à disciplina: caso a maioria das respostas apontasse para muito difícil (5) ou não difícil (0) poderíamos concluir que esta é a 
característica da disciplina, mas devido à grande variação das respostas é possível que elas reflitam o grau de envolvimento de cada um com a atenção às aulas, atividades, trabalhos, afinidade com o professor, afinidade com os colegas, entre outras variáveis que afetam a dificuldade de estudantes diante de assuntos abordados na escola.

Ao responderem sobre a própria capacidade de desenvolver programas ou aplicativos úteis para si, as respostas foram bem variadas. É possível que apenas um ano cursando a disciplina não seja tempo suficiente para desenvolver a confiança dos estudantes nas suas próprias capacidades, minando a percepção do PC como ferramenta de empoderamento tecnológico.

Em um âmbito escolar com uma disciplina obrigatória de PC existem diferentes possibilidades de abordagem para o assunto. Da maneira que a disciplina foi implantada em 2017 se mostrou necessário desenvolver uma base inicial com os estudantes, abordando os fundamentos da computação e do PC, assim como apresentar diferentes ferramentas que tornassem possível a aplicação destes fundamentos. Após desenvolver a base inicial foi possível iniciar uma abordagem interdisciplinar. Para trabalhos futuros podem ser realizadas parcerias com professores de outras disciplinas para aplicar o PC na construção do conhecimento de diversas áreas, formulando o plano de ensino com base neste objetivo.

As respostas referentes ao interesse em cursar a área da computação no ensino superior mostraram que a maioria não tinha interesse em cursar a área, Isto vai de encontro com a ideia proposta por Wing (2006), na qual todos devem desenvolver o PC, mas não necessariamente se tornar um cientista da computação. Mas é possível perceber que $67.7 \%$ dos respondentes demonstraram algum interesse em cursar a área, criando a possibilidade de aumentar o número de profissionais na área de computação ou afins.

Por ser uma disciplina obrigatória, muitos estudantes que não tinham afinidade com computadores se mostraram relutantes em participar das atividades e realização dos trabalhos. Através do sistema de notas, os estudantes que não possuíam esta afinidade sentiram a necessidade de realizar as atividades e trabalhos para alcançar a média ao final do ano. A participação destes estudantes proporcionou uma experiência que não seria possível caso a disciplina não fosse obrigatória. Foi possível perceber a transformação em alguns destes estudantes, que ao iniciar as atividades perceberam do que são capazes através do PC.

O sistema de notas da escola também afetou os estudantes mais esforçados e interessados no assunto. Alguns estudantes ao perceberem que alcançaram a média necessária para ser aprovado na disciplina começaram a não participar mais das aulas, não realizar os trabalhos e atividades. Ao serem questionados sobre este comportamento afirmaram que ainda tinham interesse pela disciplina, mas que estavam cansados de tantas atividades e tantos trabalhos (em outras disciplinas), e gostariam de descansar no final do ano.

Para trabalhos futuros pretende-se: apresentar a progressão da disciplina; realizar nova coleta de dados sobre os estudantes para comparar com os dados apresentados neste artigo; e mensurar o desempenho dos alunos através de testes voltados ao PC.

\subsection{Recomendações para a Implantação da Disciplina de PC}

Com base na experiência da disciplina de PC no CAU recomendamos as seguintes 
estratégias de implantação:

1. A realização de pequenos projetos práticos com temas escolhidos pelos estudantes apresenta bons resultados, entretanto é necessário observar a duração destes projetos evitando que sejam excessivamente longos, fazendo com que os estudantes se desmotivem e construam uma ideia negativa das ferramentas e estratégias utilizadas em aula.

2. A utilização de laboratório de informática é extremamente recomendada para uma disciplina de PC, entretanto, se a abordagem de projetos for adotada recomenda-se fortemente que existam 2 professores no laboratório, visto que a demanda de auxílio para as equipes é muito alta.

3. Recomendamos que as atividades no laboratório de informática sejam realizadas em duplas ou trios. As atividades realizadas individualmente, apesar de possibilitarem uma avaliação particularizada do desempenho de cada estudante, não possibilitam o desenvolvimento da capacidade de trabalhar em equipe $\mathrm{e}$ impõem a necessidade de uma grande quantidade de computadores nos laboratórios, gerando custos proibitivos para a maioria das instituições de ensino.

4. Algumas atividades podem ser realizadas em sala de aula com o telefone celular, evitando a ida até o laboratório de informática (o que consome um tempo precioso em aulas de 45 minutos). No CAU de Itajaí onde realizamos este experimento praticamente todos os estudantes possuíam telefone celular. Ainda que esta situação não represente a totalidade do Brasil sabemos que a presença dos dispositivos móveis somente tende a crescer em todas as classes sociais.

5. O tempo reduzido das aulas (45 minutos) impõe dificuldades para a realização de projetos práticos (que podem durar algumas semanas), então recomenda-se que a disciplina ocupe duas aulas por semana, e se possível duas aulas seguidas.

6. Recomendamos também que a disciplina de PC se integre com as demais disciplinas da matriz curricular, fomentando o envolvimento de professores e demais profissionais. Por exemplo, o sistema de movimentação de personagens no Scratch pode ser facilmente relacionado com atividades de matemática que abordam o plano cartesiano. Ao final do ano letivo os estudantes vivenciaram uma experiência na qual uma das atividades de uma gincana era cumprir um desafio de $\mathrm{PC}^{9}$ no laboratório de informática. O desafio foi realizado pelas equipes com muita energia, e acreditamos que este é um bom exemplo de como as atividades de PC podem se relacionar com atividades físicas, que envolvem movimento. Além disso, vale mencionar também que nesta gincana a realização da atividade não valia uma nota tradicional, porém gerava uma recompensa (maior pontuação para a equipe da gincana). Em nossa experiência ficou evidente que o sistema tradicional de notas não recompensa de maneira significativa, enquanto sistemas alternativos, como a gincana, parecem gerar bons resultados.

\footnotetext{
${ }^{9}$ http://gincana-cau.appspot.com/
} 


\section{References}

Aono, A. H., Rody, H. V. S., Musa, D. L., Pereira, V. A. e Almeida, J. (2017) “A Utilização do Scratch como Ferramenta no Ensino de Pensamento Computacional para Crianças” In: 25 WEI - Workshop sobre Educação em Computação

DeLyser, L. A., Mascio, B. e Finkel, K. (2016) "Introducing Student Assessments with Evidence of Validity for NYC's CS4All” In: Proceedings of the 11th Workshop in Primary and Secondary Computing Education

Dettori, L., Greenberg, R.I., McGee, S., Reed, D. (2016) “The impact of the exploring computer science instructional model in Chicago Public Schools" In: Computing in Science \& Engineering

Heintz, F., Mannila, L. e Färnqvist, T. (2016) “A Review of Models for Introducing Computational Thinking, Computer Science and Computing in K-12 Education” In: Frontiers in Education Conference. Los Alamitos.

Reis, F. de M., Oliveira, F. C. S., Martins, D. J.da S. e Moreira, P. da R. (2017) "Pensamento Computacional: Uma Proposta de Ensino com Estratégias Diversificadas para Crianças do Ensino Fundamental" In: Anais do Workshop de Informática na Escola. Vol. 23.

Sabbagh, S. A., Gedawy, H., Alshikhabobakr, H. e Razak, S. (2017) "Computing Curriculum in Middle Schools: An Experience Report" In: ACM Conference on Innovation and Technology in Computer Science Education

Santos, W. O. dos (2017) "Mulheres na Computação: Uma Análise da Participação Feminina nos Cursos de Licenciatura em Computação" In: Workshops do VI Congresso Brasileiro de Informática na Educação, Recife.

Souza, I. M. L., Rodrigues, R. S. e Andrade, W. L. (2016) "Introdução do Pensamento Computacional na Formação Docente para Ensino de Robótica Educacional” In: Workshops do Congresso Brasileiro de Informática na Educação, Uberlândia.

Wing, J. M. (2006) “Computational Thinking” In: Communications of the ACM, v.49, n.3, p.33-35. 